\title{
Characterization of Plasma-deposited a-C:H:Si:F:N Films
}

\author{
Juliana Feletto Silveira Costa Lopes ${ }^{a}$, Felipe de Oliveira Furquim ${ }^{a}$, Elidiane Cipriano Rangel ${ }^{a}$ (1), \\ Steven F. Durrant ${ }^{a^{*}}$ (D) \\ "Universidade Estadual Paulista “Júlio de Mesquita Filho” (UNESP), Instituto de Ciência e \\ Tecnologia, Sorocaba, SP, Brasil.
}

Received: January 10, 2021; Revised: April 15, 2021; Accepted: June 16, 2021

\begin{abstract}
Thin a-C:H:Si:F:N films were studied as a function of the partial pressure of $\mathrm{SF}_{6}$ in plasma feed, $\mathrm{R}_{\mathrm{SF}}$, together with tetramethylsilane and $\mathrm{N}_{2}$. Deposition rates varied from $\sim 4$ to $\sim 19 \mathrm{~nm}$. $\mathrm{min}^{-1}$. Surface roughnesses were typically less than $35 \mathrm{~nm}$. Surface contact angles with water droplets, measured using goniometry, were all around $90^{\circ}$. Scanning electron micrography revealed surface particles, probably formed in the gas phase, of typical diameters $\sim 8 \mu \mathrm{m}$. As revealed by Fourier transform infrared spectroscopy and energy dispersive $\mathrm{x}$-ray spectroscopy, the films are plasma polymers with a carbon and silicon network. Most of the films contain $\sim 60$ at.\% C, 10 at.\% Si, 20 at.\% O and $\sim 5$ to 14 at. $\%$ N. Film doping with $\mathrm{F}$ rises to $\sim 2$ at. $\%$ as $\mathrm{R}_{\mathrm{SF}}$ is increased. The Tauc gap, calculated from ultraviolet-visible near infrared spectroscopic data, is controllable in the range of $\sim 3.5$ to $4.1 \mathrm{eV}$ by a suitable choice of $\mathrm{R}_{\mathrm{SF}}$. Fluorination causes the films to be softer and less stiff. Total deformation and stored energies are reduced compared to those of the film deposited at $\mathrm{R}_{\mathrm{SF}}=0 \%$. The modulus of dissipation increases from $\sim 8 \%$ to a maximum of $\sim 65 \%$ for the fluorinated films.
\end{abstract}

Keywords: PECVD, a-C:H:Si:F:N, thin films, optical properties.

\section{Introduction}

Diverse amorphous films containing some of the elements $-\mathrm{C}, \mathrm{H}, \mathrm{Si}, \mathrm{N}$ and $\mathrm{F}$ - have been studied in recent decades. For example, amorphous hydrogenated carbon films also containing nitrogen and fluorine, designated a-C:H:N:F, were produced in a parallel-plate, capacitively coupled reactor by Liu et al. ${ }^{1}$ from $\mathrm{CH}_{4}-\mathrm{N}_{2}-\mathrm{NF}_{3}$ mixtures. As the concentration of nitrogen and fluorine increases in the films the $\mathrm{sp}^{2} / \mathrm{sp}^{3}$ ratio increases at the expense of the hydrogen content. The resulting films showed improved thermal stability of their electrical conductivity. Additional studies by the same research group indicate that the Tauc gap decreases and the Urbach energy increases as film [N] and $[\mathrm{F}]$ increase, producing defect states within the gap ${ }^{2}$.

Owing to their low dielectric constants, SiOF films find possible application as interlayer dielectrics ${ }^{3}$. Plasma enhanced chemical vapor deposition (PECVD) has been used to produce a-Si:N:F films from $\mathrm{SiH}_{4}, \mathrm{~N}_{2}$, Ar and $\mathrm{NF}_{3}$ mixtures ${ }^{4}$. The refractive index of the films fell from about 2.2 to 1.6 , while the gap increased from roughly 2.2 to $5.7 \mathrm{eV}$ as the $\mathrm{NF}_{3}$ flow rate was increased from 0 to $2 \mathrm{sccm}$. Despite its absence from the reactor feed, oxygen was incorporated into the deposited material. Film density fell as the $\mathrm{NF}_{3}$ flow rate increased from 0.5 to $2 \mathrm{sccm}$.

Nanometric fluorinated silicon nitride films were produced at $350^{\circ} \mathrm{C}$ in the down flow of an electron cyclotron resonance PECVD reactor fed $\mathrm{NH}_{3}-\mathrm{SiF}_{4}$ mixtures ${ }^{5}$. Such films, which exhibit extremely low leakage currents, may serve as gate dielectrics. Plasma immersion ion implantation and deposition

"e-mail: steven.durrant@unesp.br
(PIIID) has been used to deposit a-C:H:Si:O:F films from hexamethyldisiloxane (HMDSO)- $\mathrm{SF}_{6}-\mathrm{Ar}_{\text {mixtures }}{ }^{6}$. The films showed hardnesses of $\sim 1.5 \mathrm{GPa}$.

Despite such studies, there is little extant literature on a-C:H:Si:F:N films. In this study we characterize films deposited from cold plasmas fed tetramethylsilane (TMS) $-\mathrm{SF}_{6}-\mathrm{N}_{2}$ mixtures.

\section{Materials and Methods}

The deposition system is shown in Figure 1. Films were deposited in a cylindrical glass chamber, containing two circular, horizontal, parallel-plate electrodes. Radiofrequency (13.56 MHz) power was fed from a supply (TOKYO HY-POWER, MB-300) at $70 \mathrm{~W}$ to the lower electrode via a matching network, used to minimize the reflected power. The upper electrode was earthed. Pressure was monitored using a Pirani gauge (AGILENT, PCG-750). Nitrogen and sulfur hexafluoride gases (99.95\% pure, WHITE MARTINS, Brazil) were admitted to the chamber from cylinders via precision leak valves (EDWARDS, LV10-K). For tetramethylsilane (TMS), vapor was introduced from a vial of the liquid reagent. For depositions, the chamber was evacuated continuously using a rotary vane pump (EDWARDS, E2M18). A TMS partial pressure of 96 mTorr was maintained for all depositions. The total pressure of nitrogen and sulfur hexafluoride was 24 mTorr. For all depositions, a time of 30 min was used. The stoichiometry of the films was altered by increasing the partial pressure of $\mathrm{SF}_{6}$ in the feed, $\mathrm{R}_{\mathrm{SF}}$ and decreasing that of nitrogen by the same amount. 


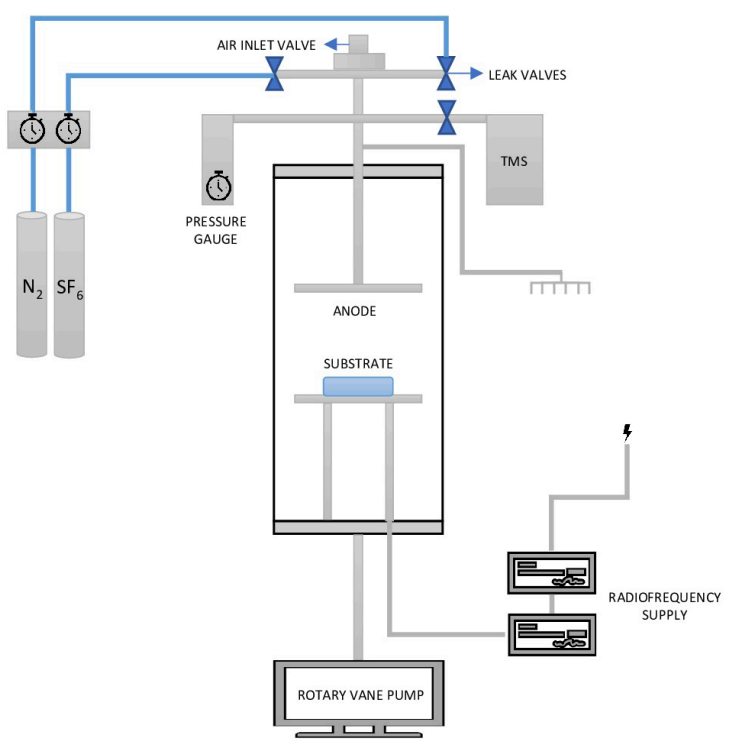

Figure 1. PECVD system.

Substrates, placed on the lower electrode, were of glass, polished stainless steel, and quartz. The glass substrates were used for films examined by Profilometry and Goniometry. Polished stainless-steel substrates were used for films examined by Infrared Reflection Absorption Spectroscopy (IRRAS), Scanning Electron Microscopy (SEM) and Energy-dispersive X-ray Spectrometry (EDS). Quartz substrates were employed for films examined by Ultraviolet-visible Near Infrared Spectroscopy (UVS) and nanoindentation.

Film deposition rates were calculated using Equation 1, where $\mathrm{R}$ is the deposition rate, $\mathrm{h}$ is the film thickness and $\mathrm{t}$ the deposition time.

$$
R=h / t
$$

Film thickness was measured from a film deposited onto a glass slide partially covered by an adhesive tape. Subsequent removal of the tape produced a well-defined film edge, which was measured using Profilometry (VEECO DekTak 150). Film surface roughness was calculated using the arithmetic method from film surface profiles. Surface morphology was examined using SEM (JEOL JSM-6010LA) and elemental analysis carried out using an EDS accessory (DRY SD Hyper (EX 94410T1L11)).

For Infrared Reflection Absorption Spectroscopy (IRRAS) a JASCO FTIR-410 spectrometer operating over the wavenumber range from 400 to $4000 \mathrm{~cm}^{-1}$ was used. A resolution of $4 \mathrm{~cm}^{-1}$ was achieved. Each spectrum was obtained using 128 scans.

From film thickness measurements and transmission UVS spectra obtained with a PERKIN ELMER LAMBDA 750 , refractive indices and optical gaps were calculated using procedures described in detail elsewhere ${ }^{7,8}$. Surface contact angles were measured on drops of distilled deionized water and diiodomethane using a KRÜSS DSA25E Goniometer. For each of three drops placed at different positions on the film, ten measurements were taken.
The hardness, elastic modulus, and stiffness of the deposited material were calculated from force-depth plots obtained using a HYSITRON Triboindenter ${ }^{9}$. A normal force was applied to a pyramidal Berkovich diamond tip in the range 150 to $3000 \mu \mathrm{N}$. Twenty indentations at each of at least 10 points were made. The three mechanical properties were calculated using the method developed by Oliver and Pharr $^{10}$. Mean values and standard deviations of the hardnesses obtained at $15 \%$ of the film thickness are presented.

\section{Results and Discussion}

Figure 2 shows the deposition rate as a function of the partial pressure of sulfur hexafluoride in the feed, $\mathrm{R}_{\mathrm{SF}}$. Film thicknesses are given in the figure caption. The rise and subsequent fall in $\mathrm{R}$ as a function of $\mathrm{R}_{\mathrm{SF}}$ is typical of systems in which the fluorine or fluorine-containing component of the chamber feed is increased. Initially, the fluorine released in the plasma causes extensive fragmentation of the monomer producing film precursors such as $\mathrm{CH}_{\mathrm{x}}$ and $\mathrm{CF}_{\mathrm{x}}$ as well as volatile $H F$, but at greater $\mathrm{R}_{\mathrm{SF}}$ etching begins to dominate and the deposition rate falls. Hydrocarbon polymers are readily etched in oxygen-containing plasmas via reactions such as that shown in Equation 2:

$$
\mathrm{C}_{x} \mathrm{H}_{y}(s)+\mathrm{O}_{2}(g) \rightarrow \mathrm{CO}(g)+\mathrm{H}_{2} \mathrm{O}(g)
$$

Polymers containing $\mathrm{Si}$, however, are more readily etched in fluorine/oxygen plasmas, such as $\mathrm{CF}_{4} / \mathrm{O}_{2}$ or $\mathrm{SF}_{6} /$ $\mathrm{O}_{2}{ }^{11}$. Etching of polymers containing $\mathrm{C}$ and $\mathrm{Si}$ is likely via reactions (3) to (5), with the overall reaction being summarized by Equation 6.

$$
\begin{aligned}
& S i+m F \rightarrow S i F_{m}, m=1 \text { to } 4 \\
& C+m F \rightarrow C F_{m} \\
& C+n O \rightarrow C O_{n}, n=1 \text { to } 2
\end{aligned}
$$

$2 \mathrm{SiC}+3 m \mathrm{~F}+n \mathrm{O} \rightarrow 2 \mathrm{SiF}_{m}+\mathrm{CO}_{n}+C F_{m}$

These reactions are given by Yih et al. ${ }^{2}$ for etching of $\mathrm{SiC}$. In the present case the plasmas are depositing and causing etching. Although not deliberately introduced into the reactor feed, some residual oxygen is present. Silicon, hydrogen, and nitrogen are present in the chamber feed. Fluorine is present in the plasmas for which $\mathrm{R}_{\mathrm{SF}}$ is not zero.

Post-deposition reactions between free radicals trapped in the film and ambient oxygen and water vapor are known to occur in plasma polymers ${ }^{13,14}$, thus attaching $\mathrm{O}$ and $\mathrm{OH}$ to the film surface. The initial base pressure also represents a possible source of oxygen for the plasma. In addition, despite extensive cleaning of the reactor before each deposition, degasification from the chamber walls is another possible source of oxygen.

Sulfur was not detected in the films by EDS. As $\mathrm{SF}_{\mathrm{n}}(\mathrm{n}=1$ to 6$)$ species are present in the plasma, sulfur may be removed as volatile products, such as SOF and $\mathrm{SO}_{2}$, formed by reactions that occur in $\mathrm{SF}_{6}$ plasmas ${ }^{15}$, and described in Equations 7 and 8.

$\mathrm{SF}_{2}+\mathrm{O} \rightarrow \mathrm{SOF}+\mathrm{F}$ 
$\mathrm{SOF}+\mathrm{O} \rightarrow \mathrm{SO}_{2}+\mathrm{F}$

An additional factor influencing the plasma conditions is that the electron energy distribution function and density depend on the components of the plasma feed. As revealed by optical emission spectroscopy, the species $\mathrm{H}, \mathrm{CH}$ and $\mathrm{CN}$ are present in cold plasmas fed TMS-N $-\mathrm{He}-\mathrm{Ar}{ }^{16}$. It is well known that the presence of dangling bonds on the film surface probably enhances the sticking probability of carbon-containing radicals. Plasma F radicals in plasmas containing fluorine remove hydrogen, leaving dangling bonds, while $\mathrm{CF}_{\mathrm{x}}$ radicals contribute to film growth.

Figure 3 shows the surface roughness as a function of $\mathrm{R}_{\mathrm{SF}}$. There is no systematic variation, but all the roughnesses have small absolute values, being less than $40 \mathrm{~nm}$. Roughnesses of about 5 to $80 \mathrm{~nm}$ were observed for PECVD films produced from $\mathrm{HMDSO}_{-\mathrm{SF}_{6}}$-Ar mixtures ${ }^{6}$.

The surface contact angle, $\theta$, of all the films, shown as a function of $\mathrm{R}_{\mathrm{SF}}$ in Figure 4, is fairly uniform, remaining close to $90^{\circ}$, i.e. close to the region defining hydrophobic surfaces. Although $\theta$ is not a strong function of $\mathrm{R}_{\mathrm{SF}}$ it shows increases

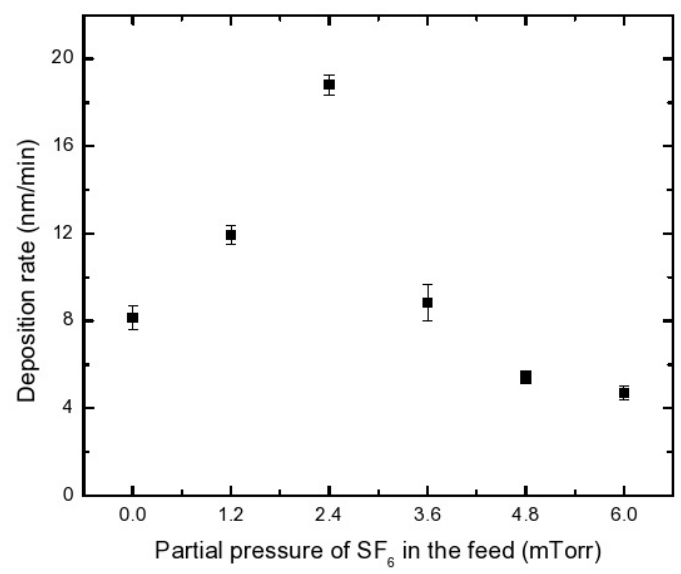

Figure 2. Deposition rate as a function of $\mathrm{R}_{\mathrm{SF}}$. Film thicknesses (nm) for films at increasing values of $\mathrm{R}_{\mathrm{SF}}: 245,358,564,265,163,141$.

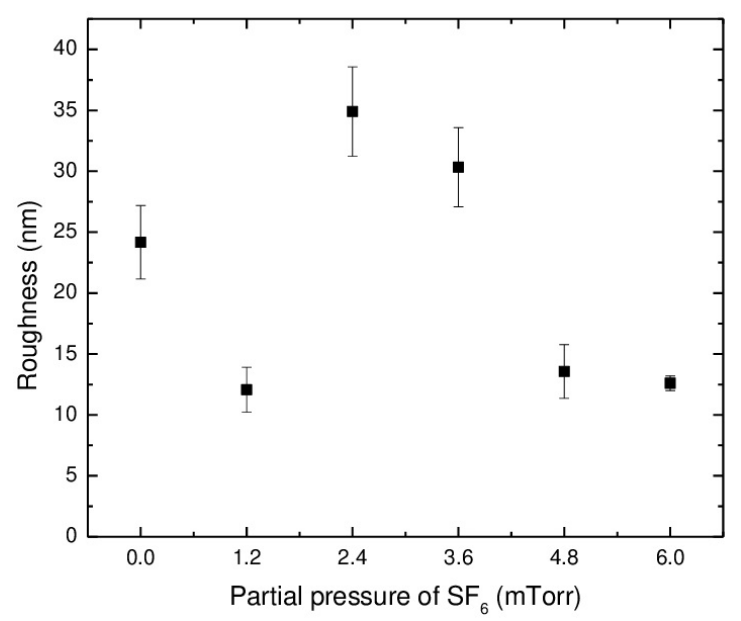

Figure 3. Surface roughness as a function of $\mathrm{R}_{\mathrm{SF}}$. and decreases that match the behavior of the roughness (Figure 3). Therefore, despite the expected structural and compositional changes in the films as $\mathrm{R}_{\mathrm{SF}}$ increases, together with modification of the surface roughness, all of which can influence $\theta$, little net change in $\theta$ is produced. The water surface contact angle of all the films is greater $\left(\sim 100^{\circ}\right)$ than that of glass $\left(\sim 60^{\circ}\right)$. For hydrophobic material, greater fluorine content is expected to produce greater values of $\theta$. As shown below, however, the films are only doped with fluorine to a maximum of about 2 at. $\%$; therefore [F] does not greatly influence $\theta$.

Total surface energy calculated from the contact angles of drops of distilled deionized water and diiodomethane are shown, together with the dispersive and polar components, as a function of $\mathrm{R}_{\mathrm{SF}}$ in Figure 5. The surface energy of glass is greater than that of the films. Non-zero values of $R_{S F}$ lead to lower polar but greater dispersive components.

Figure 6 shows scanning electron micrographs of films deposited at different $\mathrm{R}_{\mathrm{SF}}$. Each pair of micrographs $(\mathrm{a}, \mathrm{b})$ etc. shows a micrograph and at $2500 \mathrm{X}$ and at a suitable greater magnification to reveal details of a particle on the

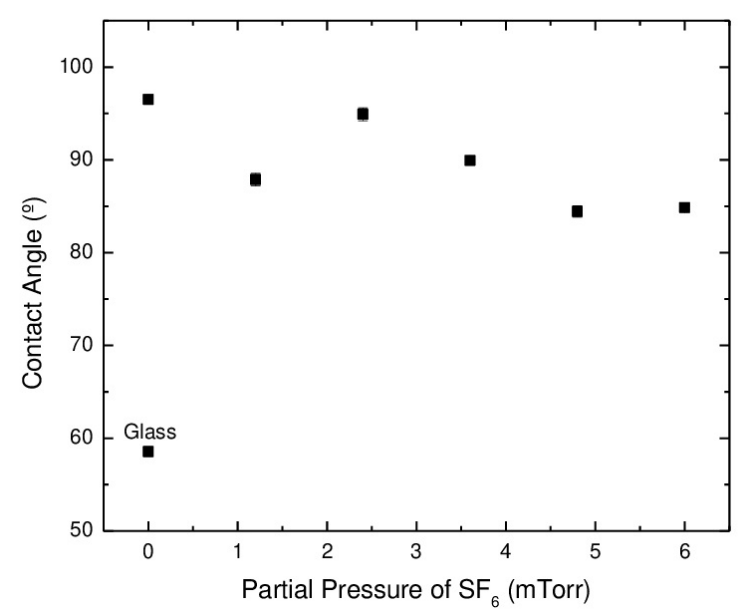

Figure 4. Contact angle as a function of $\mathrm{R}_{\mathrm{SF}}$.

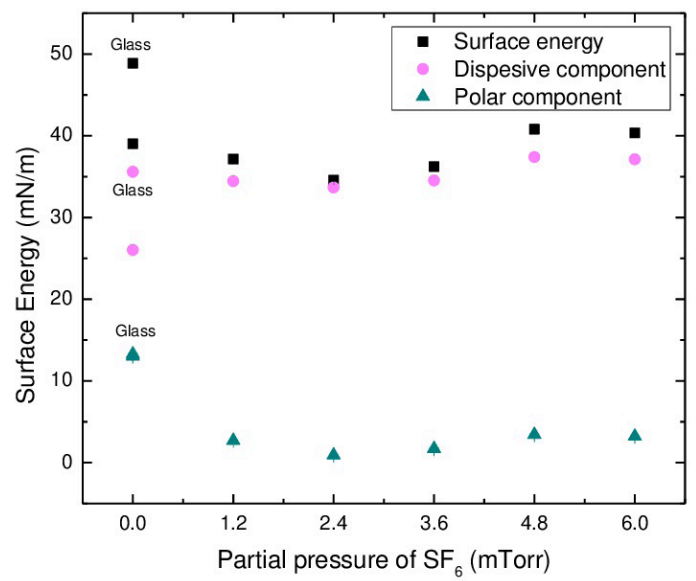

Figure 5. Total surface energy, polar, and dispersive components as a function of $\mathrm{R}_{\mathrm{SF}}$ 


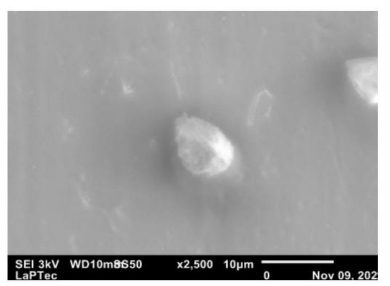

(a) 0 mTorr $\mathrm{SF}_{6}$

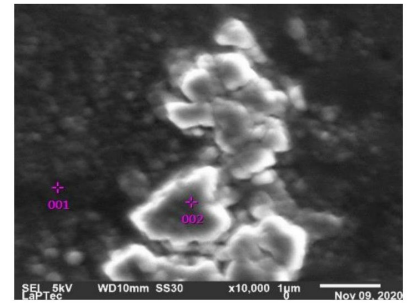

(d) $1.2 \mathrm{mTorr} \mathrm{SF}_{6}$ (EDS)

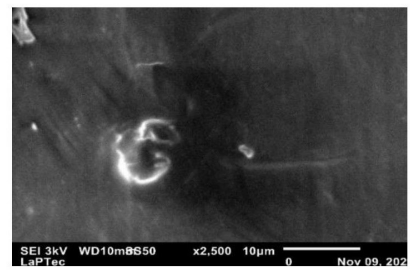

(g) 3.6 mTorr SF 6

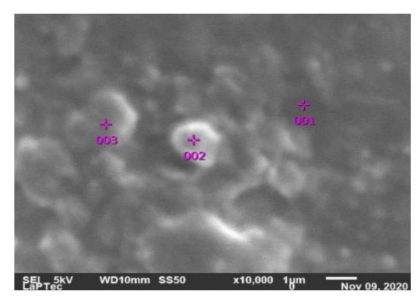

(j) 4.8 mTorr SF$_{6}$ (EDS)

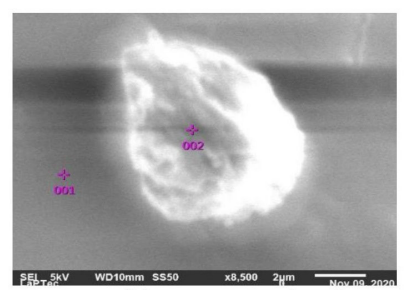

(b) 0 mTorr SF$_{6}$ (EDS)

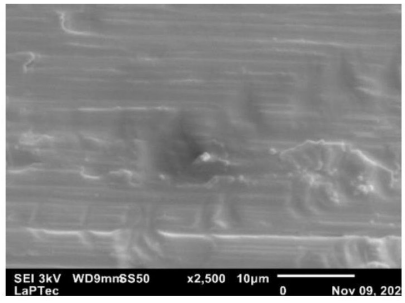

(e) 2.4 mTorr $\mathrm{SF}_{6}$

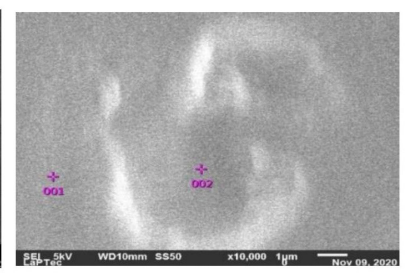

(h) $3.6 \mathrm{mTorr} \mathrm{SF}_{6}$ (EDS)

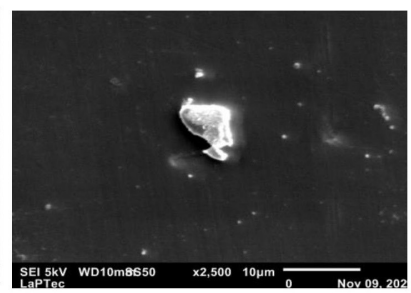

(k) 6.0 mTorr $\mathrm{SF}_{6}$

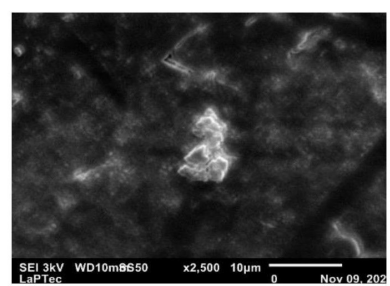

(c) $1.2 \mathrm{mTorr}^{\mathrm{SF}} 6$

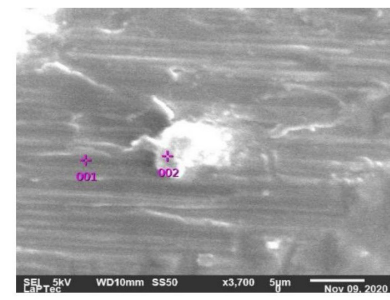

(f) 2.4 mTorr SF$_{6}$ (EDS)

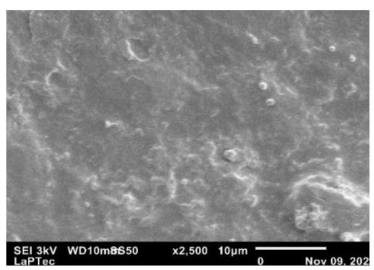

(i) $4.8 \mathrm{mTorr}^{\mathrm{SF}_{6}}$

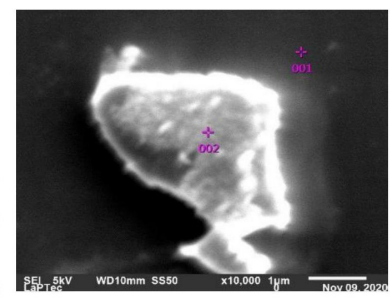

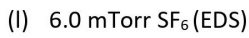

Figure 6. Scanning electron micrographs in pairs, at 2500X and at a suitable greater magnification to show details of surface particles. The micrographs were obtained for depositions at different $\mathrm{R}_{\mathrm{SF}}$ : $(\mathrm{a}, \mathrm{b}) \mathrm{R}_{\mathrm{SF}}=0$ mTorr; (c, d) $\mathrm{R}_{\mathrm{SF}}=1.2 \mathrm{mTorr}$; (e, f) $\mathrm{R}_{\mathrm{SF}}=2.4 \mathrm{mTorr}$; (g, $\mathrm{h}$ ) $\mathrm{R}_{\mathrm{SF}}=3.6$ mTorr; (i, j) $\mathrm{R}_{\mathrm{SF}}=4.8$ mTorr; $(\mathrm{k}, 1) \mathrm{R}_{\mathrm{SF}}=6.0$ mTorr. In the second micrograph of each pair, the position at which the EDS analysis was undertaken is marked.

surface. The particles are roughly spherical, with diameters of about $8 \mu \mathrm{m}$, others exhibit more complex geometries. Such particles are probably formed in the gas phase as discussed later, together with the results of the EDS analyses.

Figure 7 shows transmission IRRAS of films grown at different $\mathrm{R}_{\mathrm{SH}}$ in the 400 to $4000 \mathrm{~cm}^{-1}$ range. There is evidence of the presence of hydroxyl groups as indicated by the absorption at $3310 \mathrm{~cm}^{-1}$ in all the spectra, these being especially prominent for the film grown at 2.4 mTorr of $\mathrm{SF}_{6}$. Each film contains $\mathrm{CH}_{3}$ groups as revealed by the absorptions at 2960 and $2870 \mathrm{~cm}^{-1}$ attributed to $\mathrm{sp}^{3} \mathrm{CH}_{3}$ asymmetric vibrations and $\mathrm{sp}^{3}$ symmetric vibrations, respectively. These groups exist in the original TMS molecules, each of which contains four methyl groups. An absorption caused by $\mathrm{Si}-\mathrm{CH}_{3}$ at around $1260 \mathrm{~cm}^{-1}$, visible in all the spectra, may also be readily formed by fragmentation of TMS molecules. The prominent absorption at around $1040 \mathrm{~cm}^{-1}$ may be attributed to $\mathrm{Si}-\mathrm{O}-\mathrm{Si}, \mathrm{Si}-\mathrm{O}-\mathrm{C}$ and $\mathrm{Si}-\mathrm{CH}_{2}-\mathrm{Si}$ structures.

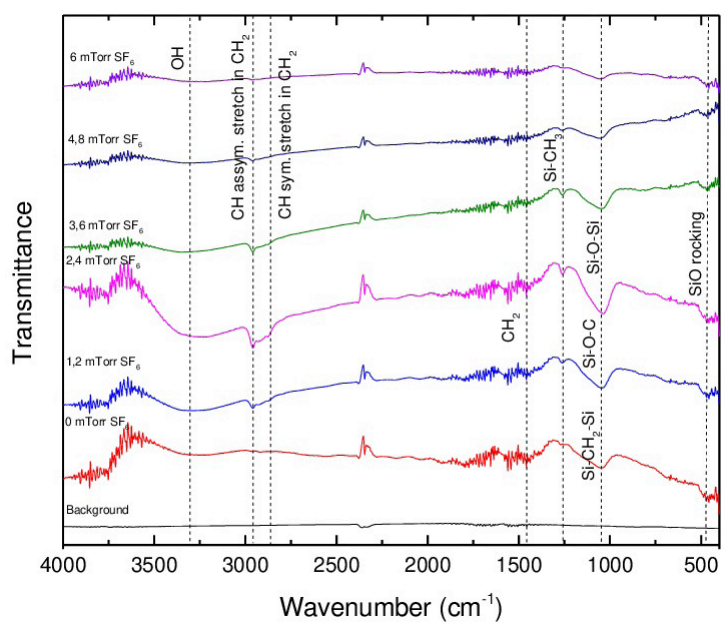

Figure 7. IRRAS spectra off the films deposited at different $\mathrm{R}_{\mathrm{SF}}$. 
As the absorptions of these three groups fall closely in the same region, it is difficult to distinguish between them. The presence of $\mathrm{Si}-\mathrm{O}-\mathrm{Si}$ and $\mathrm{Si}-\mathrm{O}-\mathrm{C}$, however, is supported by the small absorption around $460 \mathrm{~cm}^{-1}$ observed in the spectra of all the films. As mentioned above, oxygen is usually present in plasma polymers even when no oxygen is deliberately introduced into the plasma feed. No absorptions caused by fluorinated or nitrogenated functionalities are evident in any of the spectra.

Figures $8(\mathrm{a}, \mathrm{b})$ show the elemental concentrations, [C], $[\mathrm{O}]$ and $[\mathrm{Si}]$, and $[\mathrm{N}]$ and $[\mathrm{F}]$, respectively, in the films as a function of $\mathrm{R}_{\mathrm{SF}}$ as determined using EDS. Inspection of Fig. 8a reveals that the carbon content increases about 50\% and the silicon content more than doubles as $\mathrm{R}_{\mathrm{SF}}$ increases; thus the silicon content increases more relative to the carbon content. In the absence of $\mathrm{SF}_{6}$ from the feed, there is negligible incorporation of oxygen. For non-zero $\mathrm{R}_{\mathrm{SF}}$, however, $\sim 20$ at. \% oxygen is found in all the films. Thus the presence of fluorine in the plasma possibly promotes the incorporation of oxygen radicals into the growing film.

Figure $8 \mathrm{~b}$ reveals that the nitrogen content varies between about 5 and 13 at.\% as $\mathrm{R}_{\mathrm{SF}}$ is varied. As $\mathrm{R}_{\mathrm{SF}}$ increases, the partial pressure of nitrogen decreases, but only by a maximum of 6 mTorr. Thus [N] is reduced compared to that observed at $\mathrm{R}_{\mathrm{SF}}$ of zero, but the decline is not monotonic. Indeed, after an initial fall, [N] increases beyond an $\mathrm{R}_{\mathrm{SF}}$ of 2.4 mTorr. The minimum in $[\mathrm{N}]$ corresponds to the maximum deposition rate (Figure 2) at an $\mathrm{R}_{\mathrm{SF}}$ of 2.4 mTorr.

Figure $8 \mathrm{c}$ shows $[\mathrm{C}],[\mathrm{O}]$ and [Si] in the surface particles observed by SEM at different $\mathrm{R}_{\mathrm{SF}}$. Figure $8 \mathrm{~d}$ shows $[\mathrm{N}]$ and [F] for the same particles. From Fig. 8c, the composition of the particles at $\mathrm{R}_{\mathrm{SF}}=0 \%$ is distinct, consisting almost entirely of $\mathrm{C}$ and $\mathrm{O}$ (and $\mathrm{H}$ ). Thus in TMS-N ${ }_{2}$ plasmas, there is strong oxygen incorporation, probably in the gas phase, since the particles have distinct compositions from the bulk of the film, together with deposition via $\mathrm{CH}_{\mathrm{x}}$ precursors. The

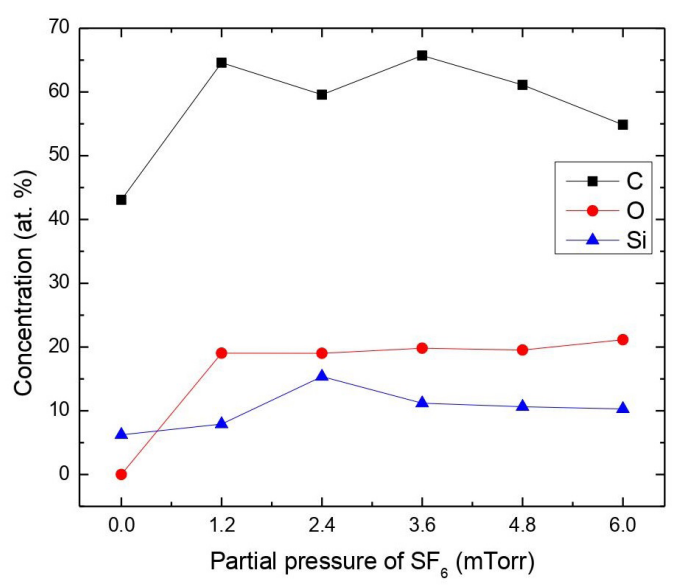

(a)

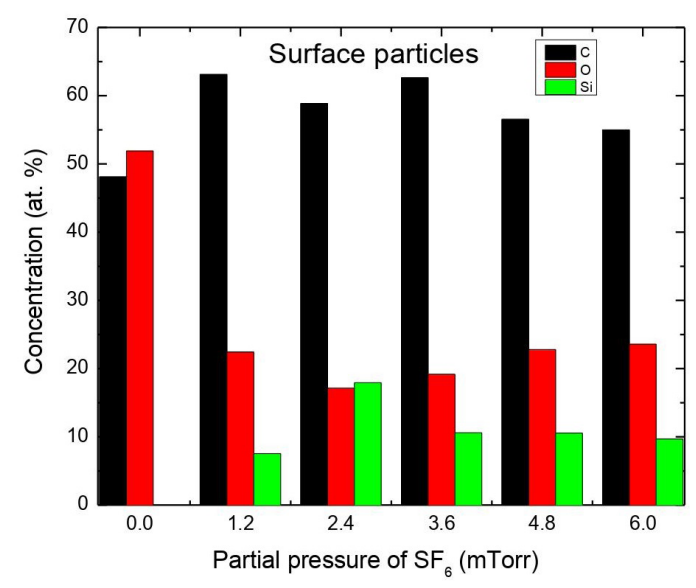

(c)

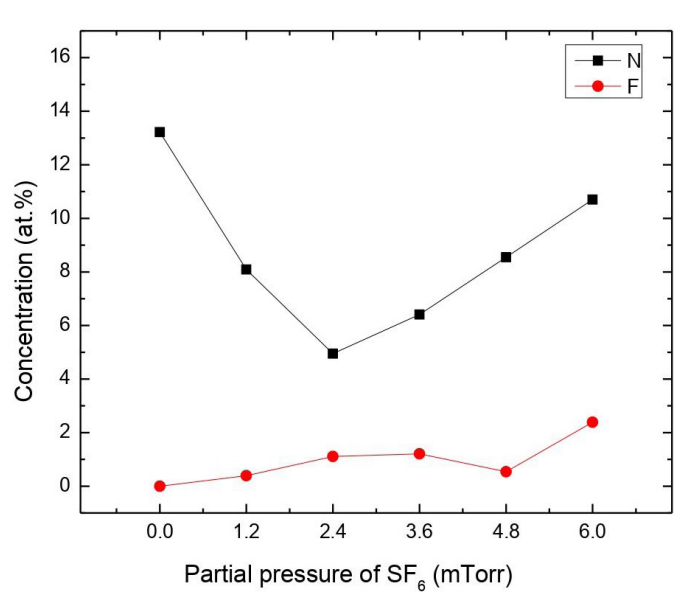

(b)

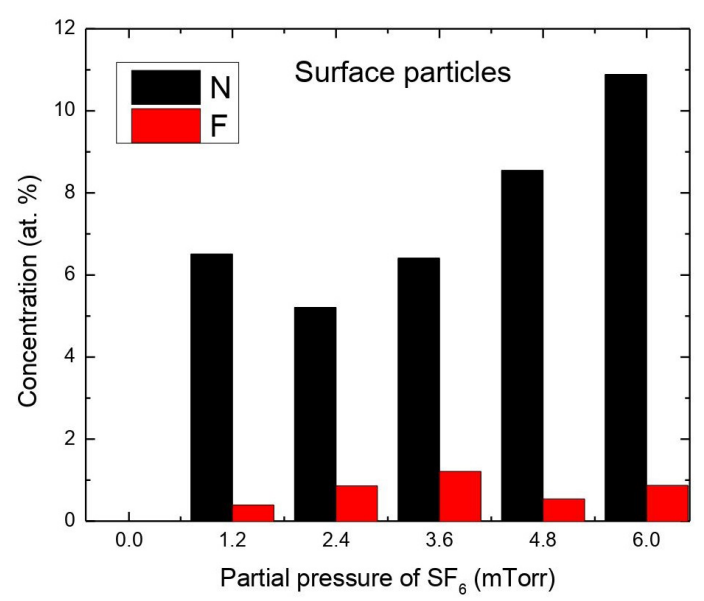

(d)

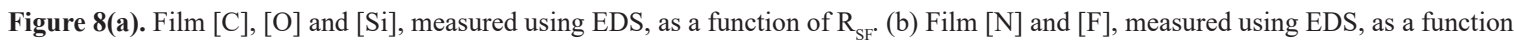
of $\mathrm{R}_{\mathrm{SF}^{*}}$ (c) Surface particle [C], [O] and [Si], measured using EDS for different $\mathrm{R}_{\mathrm{SF}}$. (d) Surface particle [N] and [F], measured using EDS for different $\mathrm{R}_{\mathrm{SF}}$. 
particles deposited at non-zero $\mathrm{R}_{\mathrm{SF}}$, contain more $\mathrm{C}, \mathrm{Si}, \mathrm{N}$ and $\mathrm{F}$, but less than half the $[\mathrm{O}]$ of the unfluorinated film.

The presence of $\mathrm{SF}_{6}$ in the chamber feed leads to a doping of the film with $\mathrm{F}$ of up to about 2 at.\%. Over the interval studied, $[F]$ rises roughly linearly with increasing $R_{S F}$, i.e. with increasing supply of $\mathrm{SF}_{6}$ to the chamber.

Figure 9 shows (where calculable) the refractive index as a function of $\mathrm{R}_{\mathrm{SF}}$. The fluorinated films exhibit lower values of $\mathrm{n}$. This behavior is consistent with that observed for the refractive index of a-Si:N:F films deposited from $\mathrm{SiH}_{4}-\mathrm{N}_{2}-\mathrm{Ar}$ mixtures ${ }^{4}$.

The Tauc gap and that defined as the energy corresponding to an absorption of $10^{4} \mathrm{~cm}^{-1}$, which has also been used to characterize the gap of amorphous materials ${ }^{17}$, are shown in Figure 10 as a function of $\mathrm{R}_{\mathrm{SF}}$. For semiconductors the bandgap is the difference in energy between the valence and conduction bands, and indicates the range of forbidden energy values for electrons. The band gap calculated, in this case, according to the Tauc model by extrapolating the linear portion of $(\alpha E)^{1 / 2}$ versus $E$ plots (where $\alpha$ is the absorption coefficient and $\mathrm{E}$ the photon energy) to its intersection with the $\mathrm{x}$-axis (i.e. the axis showing E), is designated the Tauc gap.

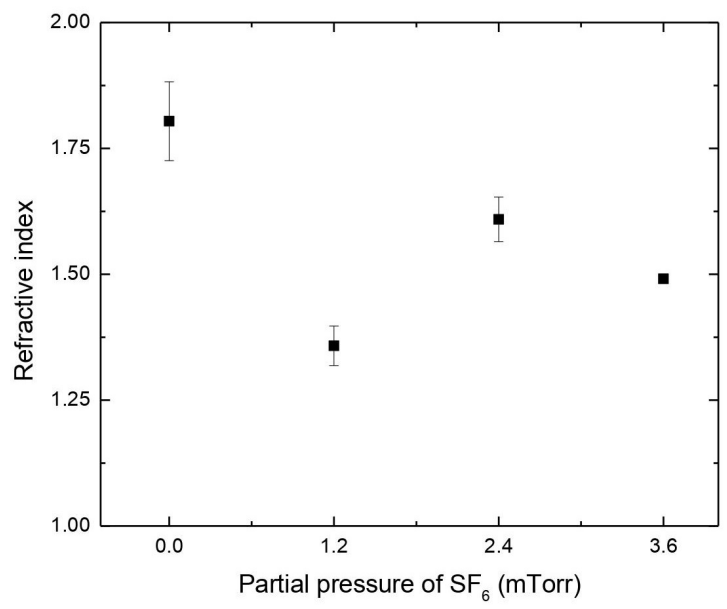

Figure 9. Refractive index of the films as a function of $\mathrm{R}_{\mathrm{SF}}$.

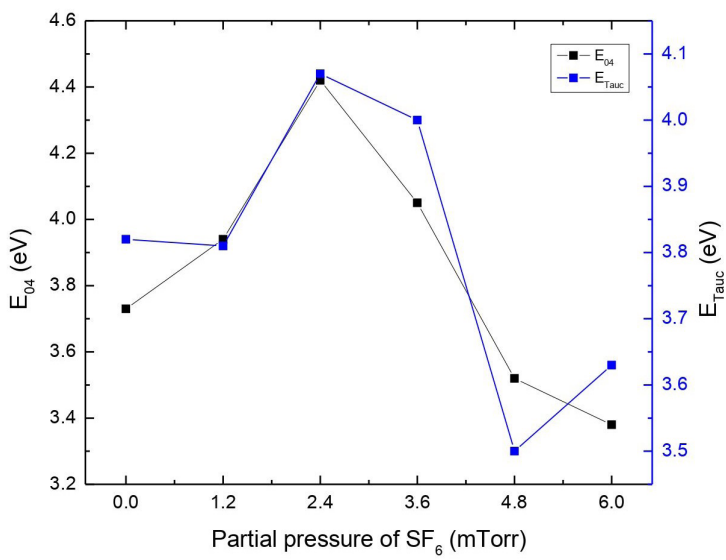

Figure 10. The Tauc and $\mathrm{E}_{04}$ optical gaps as a function of $\mathrm{R}_{\mathrm{SF}}$.
Although the absolute values of the gap differ slightly, the trends observed as a function of $\mathrm{R}_{\mathrm{SF}}$ are very similar. The unfluorinated film has a gap of $\sim 3.9 \mathrm{eV}$. Both greater and smaller gap values can be obtained by the choice of $R_{S F}$. Comparison of the behavior of film $[\mathrm{N}]$ (Figure $8 \mathrm{~b}$ ) and the optical gap (Figure 10) suggests that nitrogen introduces states into the gap, with greater film [N] tending to yield lower gaps. Together with the effect of nitrogen, doping with $\mathrm{F}$ increases steadily with $\mathrm{R}_{\mathrm{SF}}$, tending to reduce the gap. Thus at high $\mathrm{R}_{\mathrm{SF}}$ both effects combine, leading to the lowest gaps.

A typical plot of $\ln (\alpha(E))$ as a function of photon energy, $E$, used to calculate the Urbach energy, $U_{E}$ (in this case of the film deposited at $\mathrm{R}_{\mathrm{SF}}=0$ ) is shown in Figure 11. The parameter $\mathrm{U}_{\mathrm{E}}$ reflects the degree of absorption edge spreading caused by structural disorder, which forms localized states within the band tails of electronic states. Figure 12 shows $U_{E}$ as a function of the Tauc gap. The dependence of $U_{E}$ on the gap has roughly the shape expected for a semiconductor, with $\mathrm{U}_{\mathrm{E}}$ for a gap energy of $3.5 \mathrm{eV}$ being lower than expected.

The hardness, elastic modulus and stiffness of the film material calculated from nanoindentation measurements are shown as a function of $\mathrm{R}_{\mathrm{SF}}$ in Figures 13-15, respectively. All three properties are significantly lower for the fluorinated films.

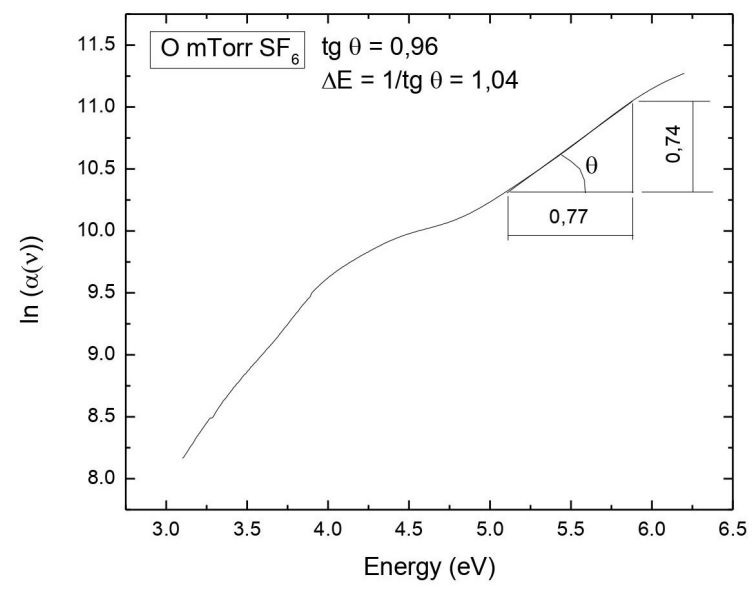

Figure 11. Example (of the unfluorinated film) of the graph allowing the calculation of the Urbach energy.

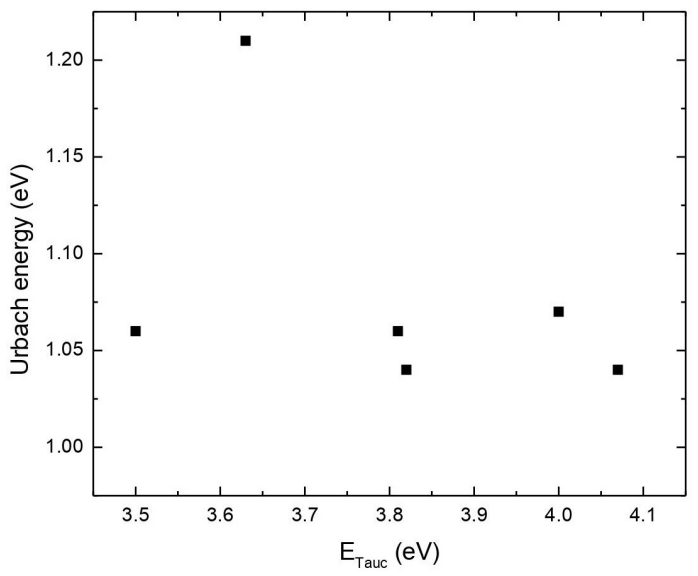

Figure 12. Urbach energy as a function of the Tauc gap. 
The hardnesses of the fluorinated films are very close to those observed in a-C:H:Si:O:F produced by Plasma Immersion Ion Implantation and Deposition of HMDSO-SF 6 -Ar mixtures, namely $1.5+/-0.1 \mathrm{GPa}^{6}$. A hardness similar to that of quartz

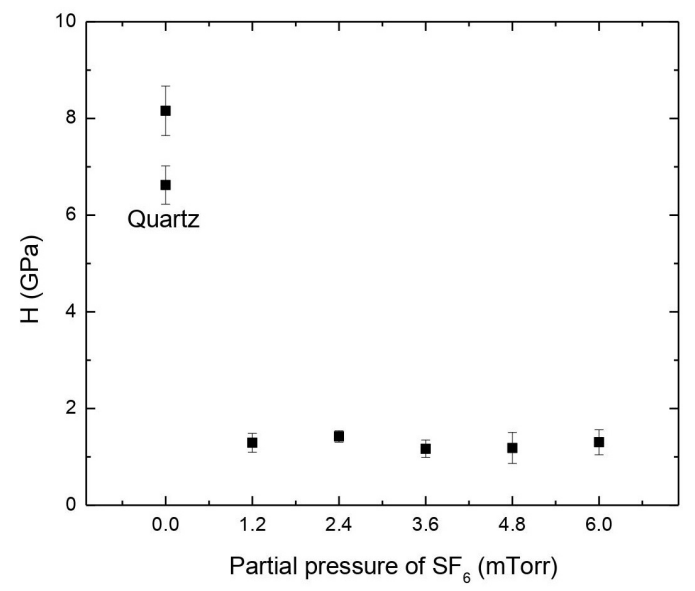

Figure 13. Hardness as a function of $\mathrm{R}_{\mathrm{SF}}$.

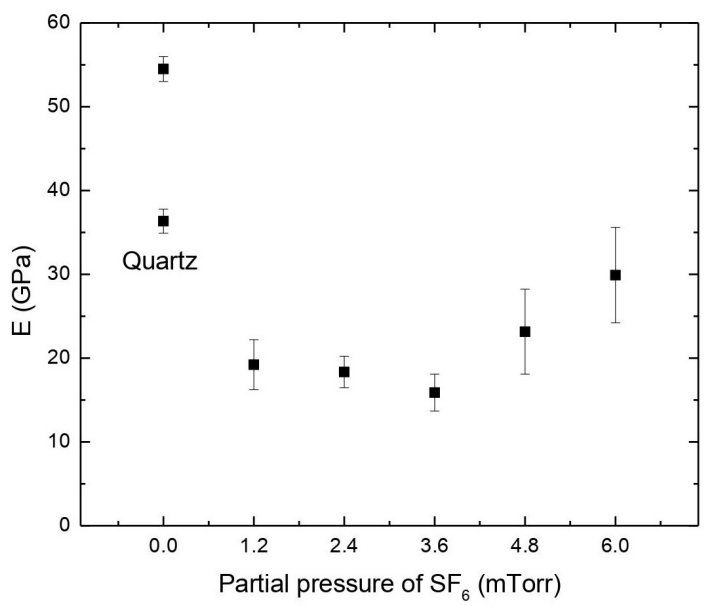

Figure 14. Young's modulus as a function of $\mathrm{R}_{\mathrm{SF}}$.

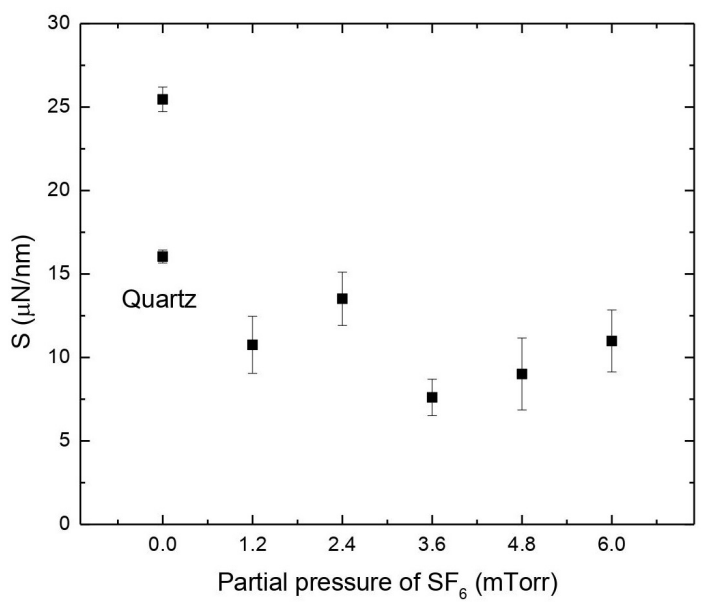

Figure 15. Stiffness as a function of $\mathrm{R}_{\mathrm{SF}}$. is observed for the unfluorinated film. A strong fall in hardness upon the incorporation of fluorine has been observed in a-C:H:F films produced from $\mathrm{CH}_{4}-\mathrm{CF}_{4}$ plasmas $^{18}$.

The parameters $\mathrm{H} / \mathrm{E}$ and $\mathrm{H}^{3} / \mathrm{E}^{2}$ are displayed as a function of $\mathrm{R}_{\mathrm{SF}}$ in Figure 16. Both parameters are greatly reduced in the fluorinated films since $\mathrm{H}$ falls by a factor of about eight when $\mathrm{SF}_{6}$ is introduced into the chamber feed. The $\mathrm{H} / \mathrm{E}$ values are indicative of ease of plastic deformation and therefore the observed fall in this parameter suggests low wear resistance for the fluorinated films. $\mathrm{H}^{3} / \mathrm{E}^{2}$ is proportional to the load at which the material deforms plastically ${ }^{19}$. Materials with high plastic deformation may be useful in certain applications, such as those used in nanoindentation lithography ${ }^{20}$.

Figure 17 shows the elastic recovery and plastic deformation energy as a function of $\mathrm{R}_{\mathrm{SF}}$. Relatively high elastic recoveries $(>90 \%)$ are observed for all the films. The plastic deformation energy tends to fall with increasing $\mathrm{R}_{\mathrm{SF}}$. Total deformation energy, stored and dissipated energy as a function of $\mathrm{R}_{\mathrm{SF}}$ are shown in Figure 18. Total deformation and stored energies are reduced at $\mathrm{R}_{\mathrm{SF}}>0 \%$. The dissipated energy is greater at non-zero $\mathrm{R}_{\mathrm{SF}}$ and greatest at $\mathrm{R}_{\mathrm{SF}}=2.4$ mTorr, which also gives an almost unchanged total deformation energy compared to that of the film deposited at $\mathrm{R}_{\mathrm{SF}}=0 \%$. The dependence of the modulus of dissipation on $\mathrm{R}_{\mathrm{SF}}$ is

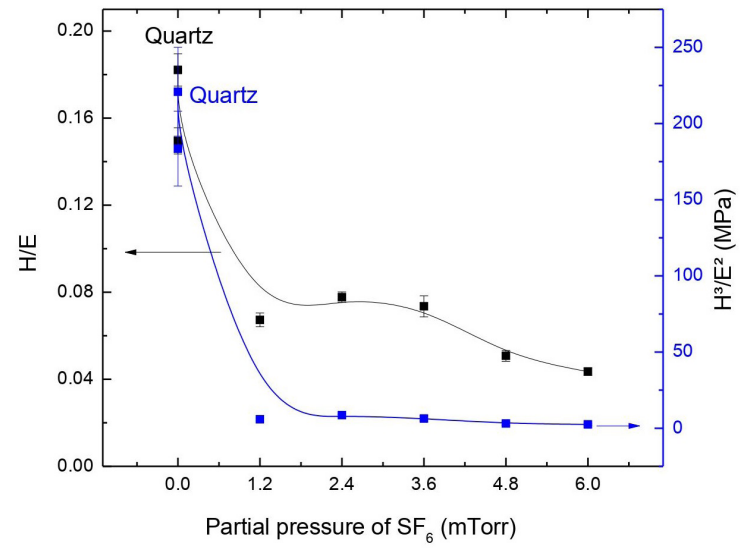

Figure 16. $\mathrm{H} / \mathrm{E}$ and $\mathrm{H}^{3} / \mathrm{E}^{2}$ as a function of $\mathrm{R}_{\mathrm{SF}}$.

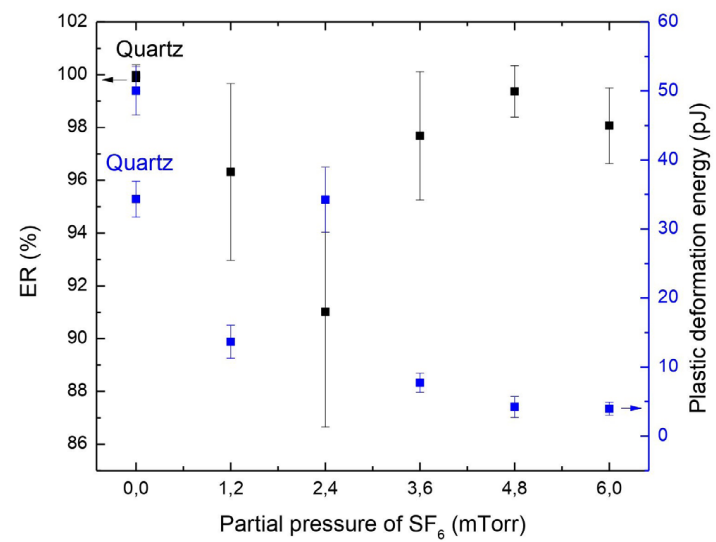

Figure 17. Elastic recovery and plastic deformation energy as a function of $\mathrm{R}_{\mathrm{SF}}$. 


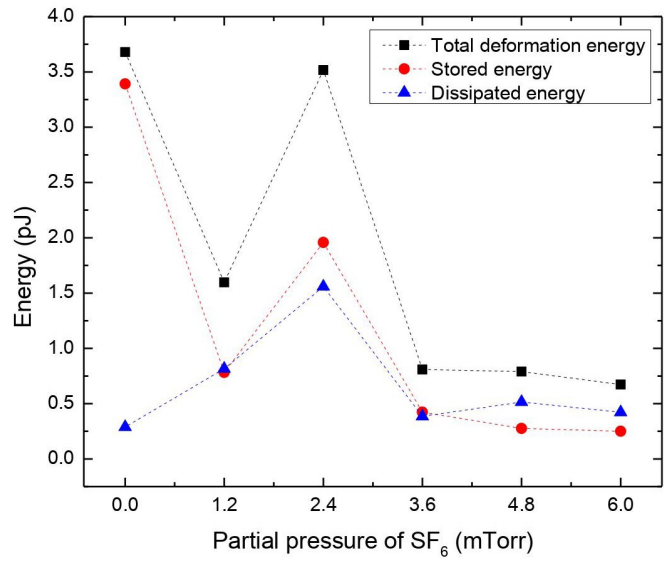

Figure 18. Total deformation, stored, and dissipated energy as a function of $\mathrm{R}_{\mathrm{SF}}$.

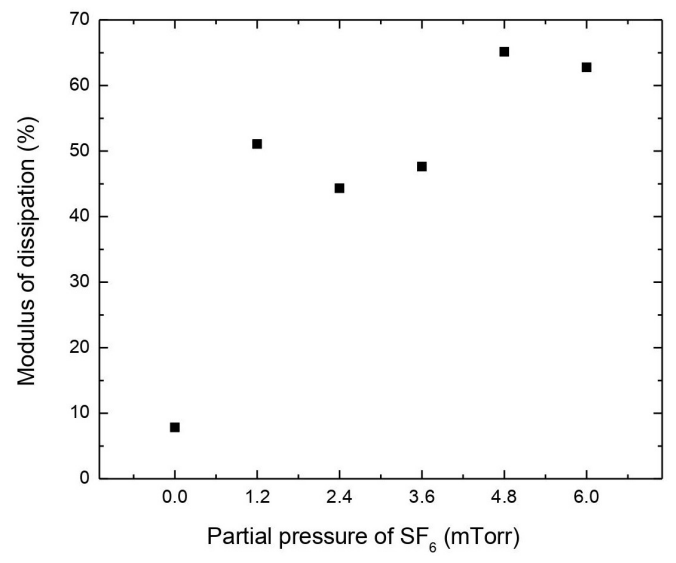

Figure 19. Modulus of dissipation as a function of $\mathrm{R}_{\mathrm{SF}}$.

depicted in Figure 19. All the fluorinated films $\left(\mathrm{R}_{\mathrm{SF}}>0\right)$ show moduli of dissipation of about 45 to $65 \%$, compared to $<10 \%$ for the unfluorinated film.

\section{Conclusions}

Amorphous hydrogenated carbon films also containing silicon and nitrogen, and doped with fluorine were obtained by the PECVD of TMS-N ${ }_{2}-S_{6}$ mixtures. As revealed by IRRAS, EDS and SEM, the films were complex plasma polymers, with surface particles of distinct elemental composition.

A maximum deposition rate of $\sim 18 \mathrm{~nm} \cdot \mathrm{min}^{-1}$ was obtained as the partial pressure of $\mathrm{SF}_{6}, \mathrm{R}_{\mathrm{SF}}$, was varied. Film roughness was less than $40 \mathrm{~nm}$ for all the films. Independently of $\mathrm{R}_{\mathrm{SF}}$, surface contact angles were all about $90^{\circ}$. Tauc gaps could be selected between 3.4 and $4.4 \mathrm{eV}$ by a suitable choice of $\mathrm{R}_{\mathrm{SF}}$. As demonstrated by nanoindentation, the fluorinated films are softer, less rigid and show greater plastic deformation than the unfluorinated film.

\section{Acknowledgments}

The authors thank FAPESP (2017/15853-0) and CNPq for financial support. This study was financed in part by the Coordenação de Aperfeiçoamento de Pessoal de Nível
Superior - Brasil (CAPES) - Finance Code 001. We thank Prof. José H. Dias da Silva for helpful discussion of the optical data.

\section{References}

1. Liu S, Gangopadhyay S, Sreenivas G, Ang SS, Naseem HA. Infrared studies of hydrogenated amorphous carbon (a-C:H) and its alloys (a-C:H,N,F). Phys Rev B Condens Matter. 1997;55(19):13020-4.

2. Liu S, Gangopadhyay S, Sreenivas G, Ang SS, Naseem HA. Photoluminescence studies of hydrogenated amorphous carbon and its alloys. J Appl Phys. 1997;82(9):4508-14.

3. Kim B-G, Kang S-Y, Kim J-J. FTIR study of fluorinated silicon oxide film. J Phys D Appl Phys. 1997;30:1720-4.

4. Jun B-H, Lee JS, Kim D-W, Sung TH, Bae BS, No K. Composition, oxidation, and optical properties of fluorinated silicon nitride film by inductively coupled plasma enhanced chemical vapor deposition. J Mater Res. 1999;14(3):995-1001.

5. Ohta H, Hori M, Goto T. Ultrathin fluorinated silicon nitride gate dielectric films formed by remote plasma enhanced chemical vapor deposition employing $\mathrm{NH}_{3}$ and $\mathrm{SiF}_{4}$. J Appl Phys. 2001;90(4):1955-61.

6. Rangel EC, da Cruz NC, Rangel RCC, Landers R, Durrant SF. Effect of ion irradiation on the structural properties and hardness of a-C:H:Si:O:F films. J Phys Conf Ser. 2015;591:012044.

7. Cisneros JI, Rego GB, Tomiyama M, Bilac S, Gonçalves $\mathrm{JM}$, Rodriguez AE, et al. A method for the determination of the complex refractive index of no- metallic thin films using photometric measurements at normal incidence. Thin Solid Films. 1983;100:155-67.

8. Tauc J. Optical properties and electronic structure of amorphous semiconductors. In: Abeles F, editor. Optical Properties of Solids. New York: American Elsevier; 1972.

9. Rangel EC, Durrant SF, Rangel RCC, Kayama ME, Landers R, Da Cruz NC. Amorphous carbon nitrogenated films prepared by plasma immersion ion implantation and deposition. Thin Solid Films. 2006;515(4):1561-7. http://dx.doi.org/10.1016/j. tsf.2006.05.016.

10. Oliver WC, Pharr GM. An improved technique for determining hardness and elastic modulus using load and displacement sensing indentation experiments. J Mater Res. 1992;7(6):156483. http://dx.doi.org/10.1557/JMR.1992.1564.

11. Szmigiel D, Domanski K, Prokaryn P, Grabiec P, Sobczak JW. The effect of fluorine-based plasma treatment on the morphology and chemical surface composition of biocompatible silicone elastomer. Appl Surf Sci. 2006;253:1506-11. http://dx.doi. org/10.1016/j.apsusc.2006.02.027.

12. Yih PH, Saxena V, Steckl AJ. A review of SiC reactive ion etching. Phys Status Solidi (b). 1997;202: 605-42.

13. Morosoff N, Crist B, Bumgarner M, Hsu T, Yasuda H. Free radicals resulting from plasma polymerization and plasma treatment. J Macromol Sci. 1976;10(3):451-71. https://doi. org/10.1080/00222337608061192.

14. Yasuda H, Bumgarner MO, Marsh HC, Morosoff N. Plasma polymerization of some organic compounds and properties of the polymers. J Polym Sci: Polym Chem Ed. 1976;14(1):195224. https://doi.org/10.1002/pol.1976.170140118.

15. Shih M, Lee WJ, Tsai C-H, Tsai P-J, Chen C-Y. Decomposition of $\mathrm{SF}_{6}$ in an RF plasma environment. J Air Waste Manage Assoc. 2002;52:1274-80. http://dx.doi.org/10.1080/10473289.2002.1 0470864 .

16. Da Cruz NC, Durrant SF, Bica de Moraes MA. Thin film deposition from plasmas of tetramethylsilane-helium-argon mixtures with oxygen and with nitrogen. J Polym Sci, B, Polym 
Phys. 1998;36:1873-9. http://dx.doi.org/10.1002/(SICI)10990488(199808)36:11<1873:AID-POLB8>3.0.CO;2-R.

17. Freeman EC, Paul W. Optical constants of rf sputtered hydrogenated amorphous Si. Phys Rev B Condens Matter. 1979;20:716. http://dx.doi.org/10.1103/PhysRevB.20.716

18. Freire FL. Amorphous hydrogenated carbon films: effects of nitrogen and fluorine incorporation on the film microstructure and mechanical properties: a review. J. Non-crystalline Solids. 2002;304(1-3):251-8.
19. Tsui TY, Pharr GM, Oliver WC, Bhatia CS, White RL, Anders $\mathrm{S}$, et al. Nanoindentation and nanoscratching of hard carbon coatings for magnetic disks. Proc MRS. 1995;383:447-52. http://dx.doi.org/10.1557/PROC-383-447.

20. Sirghi L, Ruiz A, Colpo P, Rossi F. Atomic force microscopy indentation of fluorocarbon thin films fabricated by Plasma Enhanced Chemical Deposition at low radio frequency power. Thin Solid Films. 2009;517(11):3310-4. http://dx.doi. org/10.1016/j.tsf.2009.01.055. 


\section{Erratum: Characterization of Plasma-deposited a-C:H:Si:F:N Films}

In the article "Characterization of Plasma-deposited a-C:H:Si:F:N Films", with DOI: https://doi.org/10.1590/19805373-MR-2021-0016, published in Materials Research, 24(suppl. 1):e20210016, on page 6, Figs. 11 and 12, should be as shown below:

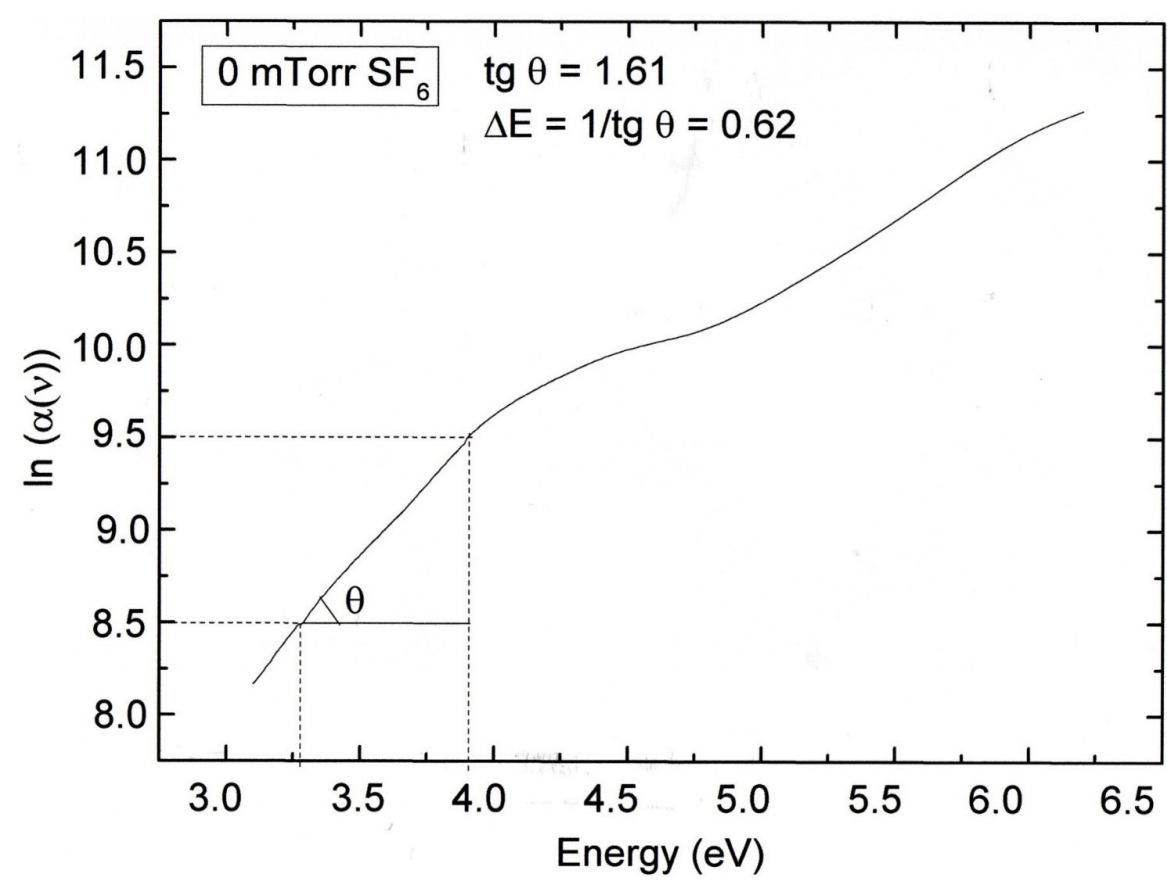

Figure 11. Example (of the unfluorinated film) of the graph allowing the calculation of the Urbach energy.

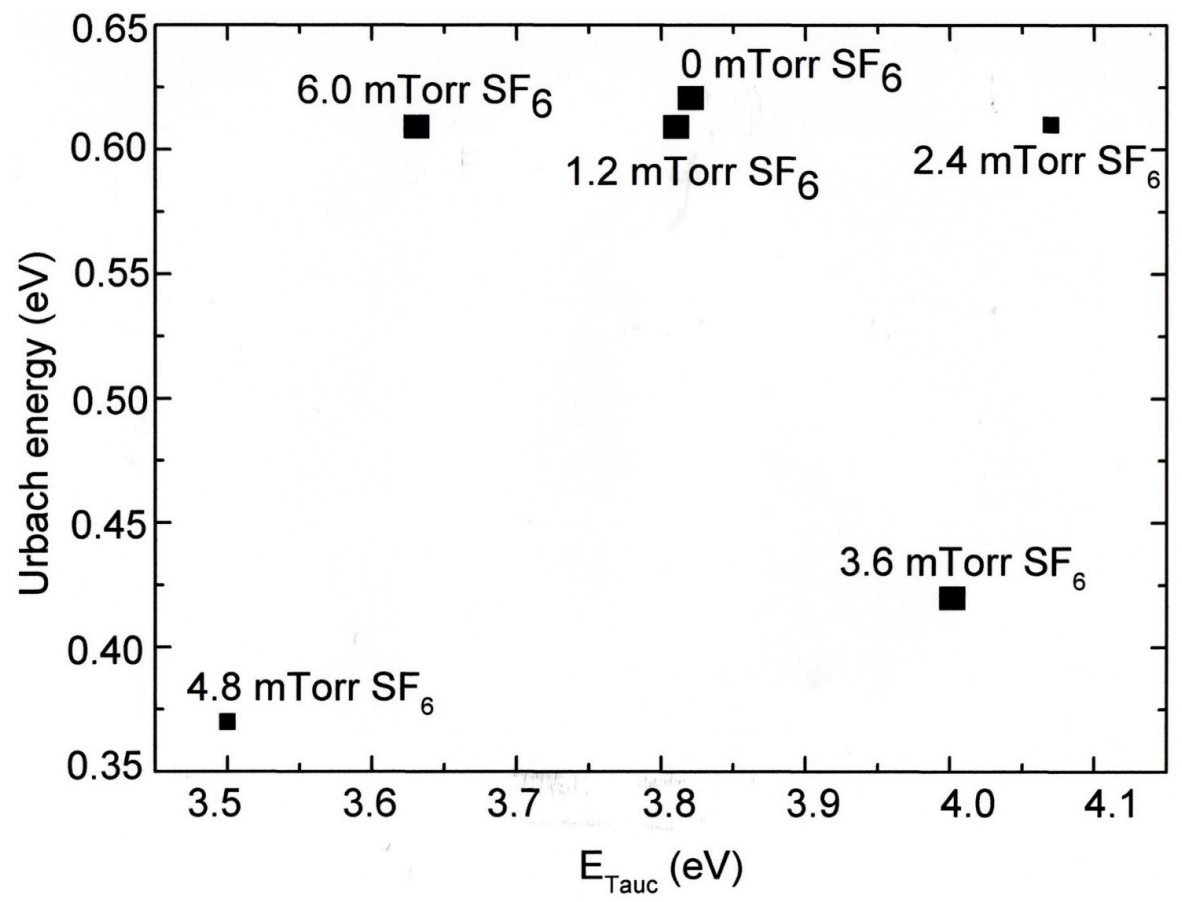

Figure 12. Urbach energy as a function of the Tauc gap. The partial pressure of $\mathrm{SF}_{6}$ used for each film deposition is given. 